\title{
Isolasi Senyawa Antioksidan dari Fraksi Etil Asetat Daun Tempuyung (Sonchus arvensis L)
}

\author{
Buyung Rukmantara Susena Putra ${ }^{a}$, Dewi Kusrini ${ }^{a^{*}}$, Enny Fachriyah $^{\text {a }}$ \\ a Organic Chemistry Laboratory, Chemistry Department, Faculty of Sciences and Mathematics, Diponegoro University, Jalan Prof. \\ Soedarto, Tembalang, Semarang \\ * Corresponding author: dewi.kusrini@live.undip.ac.id
}

Article Info

Keywords:

Sonchus arvensis L., ethyl acetate

fraction,

antioxidant,

chalcone

\section{Abstract}

Isolation of active antioxidants compounds from ethyl acetate fraction of tempuyung and activity of ethyl acetate as an antioxidant have been conducted. The identification of the structure of the active antioxidant isolates was performed by UV-VIS and antioxidants activity was determined by the DPPH (1,1-diphenyl-2-pikril-hidrazil) method. The isolated active compound derived antioxidant was a flavonoids class of chalcone. Form the antioxidant activity test, it was quantitatively known that the ethyl acetate fraction of tempuyung Sonchus arvensis $L$ leaves did not have a potential as an antioxidant with $\mathrm{IC}_{50}$ level were $353,41 \mathrm{ppm}$.
Kata Kunci:

Sonchus arvensis L., fraksi etil asetat, antioksidan, khalkon

\begin{abstract}
Abstrak
Telah dilakukan penelitian isolasi senyawa antioksidan dari fraksi etil asetat daun tempuyung serta uji aktivitas fraksi etil asetat sebagai antioksidan. Identifikasi struktur isolat aktif antioksidan dilakukan dengan spektrofotometer UV-Vis, serta aktivitas antioksidan ditentukan dengan dengan metode DPPH (1,1-difenil-2-pikril-hidrazil). Hasil isolasi senyawa aktif antioksidan diperoleh isolat A1 dan A2 yang diduga merupakan senyawa flavonoid golongan khalkon. Uji aktivitas antioksidan diketahui bahwa fraksi etil asetat memiliki potensi yang kurang bagus sebagai antioksidan dengan harga $\mathrm{IC}_{50} 353,41 \mathrm{ppm}$.
\end{abstract}

\section{Pendahuluan}

Tempuyung (Sonchus arvensis L) adalah salah satu tanaman obat tradisional yang termasuk dalam famili asteraceae. Tempuyung memiliki banyak khasiat, di antaranya untuk mengobati asam urat, diuretik [1], batu ginjal, kencing batu, bengkak, batuk, asma [2], demam, inflamasi, detoksikasi, sirkulasi darah [3]. Dalam farmakologi Cina tanaman ini memiliki rasa pahit, dingin, menurunkan panas, dan menghilangkan racun. Unsur kalium yang terkandung dalam tempuyung mampu mengikis batu ginjal. Kelarutan batu ginjal oleh tempuyung diduga melalui efek diuretiknya yaitu memperbanyak ekskresi urin. Tempuyung juga digunakan sebagai obat memar akibat benturan dengan cara menempelkan di bagian yang bengkak, menghilangkan rasa lesu dan pegal. Penelitian mengenai khasiat tempuyung juga dilakukan oleh
Wadekar $d k k$. [4] mengenai khasiat tempuyung sebagai obat cacing, diarrhoea, leucorrhoea, dan disentri.

Kandungan senyawa dalam tempuyung yang pernah dianalisis diantaranya golongan senyawa flavonoid yaitu 7,4-dihidroksi flavon, sesquiterpen dari golongan terpenoid [3], turunan asam kuinat yaitu 1,3,4,5-tetra-(p-hidroksifenilasetil dan sesquiterpen [2]. Penelitian yang pernah dilakukan oleh Radulović dkk. [5] mengenai identifikasi komponen-komponen minyak atsiri dari Sonchus arvensis L adalah heniokosan, trikosan, dan terpenoid.

Penelitian mengenai isolasi dan identifikasi senyawa metabolit sekunder telah dilakukan pada tahun 2012 yaitu flavonoid, alkaloid [6], triterpenoid [7], dan asam fenolat [8]. Berdasarkan informasi dari penelitian tersebut, penelitian ini dilakukan untuk mengisolasi dan 
mengidentifikasi senyawa aktif antioksidan fraksi etil asetat daun tempuyung (Sonchus Arvensis L) menggunakan spektrofotometer UV-Vis dan menentukan potensi fraksi etil asetat sebagai antioksidan dengan metode DPPH. Perbedaan penelitian ini dengan penelitian sebelumnya terletak pada fraksi yang diisolasi dan metode untuk menganalisis senyawanya. Pemilihan etil asetat sebagai pelarut karena diharapkan banyak senyawa antioksidan yang berupa senyawa fenolik dapat terekstrak sehingga dapat meningkatkan aktivitas antioksidan.

\section{Metode Penelitian}

Alat dan bahan

Alat yang digunakan adalah gelas beaker, erlenmeyer, gelas ukur, pipet tetes, corong pisah, chamber KLT, lampu UV, alumunium foil, pipa kapiler, rotary vaporator, botol vial, serta seperangkat alat analisis UV-Vis. Bahan yang digunakan adalah daun tempuyung dari Tawangmangu, $n$-heksana $96 \%, n-$ heksana p.a, etanol $96 \%$, etanol p.a, aseton $96 \%$, kloroform p.a, benzena p.a, diklorometana, etil asetat p.a, metanol p.a, akuades, silika gel, serbuk $\mathrm{Mg}$, amil alkohol p.a, $\mathrm{HCl} 10 \%, \mathrm{NaOH}, \mathrm{AlCl}_{3}$, eter, DPPH, Dragendroff, Meyer, Libermann-Burchard, plat KLT Merck.

Serbuk daun tempuyung sebanyak 700 gram dimaserasi dengan pelarut $n$-heksana $96 \%$. Maserasi menggunakan $n$-heksana $96 \%$ bertujuan untuk mengikat semua senyawa metabolit sekunder daun tempuyung yang bersifat non polar seperti lemak, steroid, dan triterpenoid. Filtrat yang didapatkan berwarna hijau pekat. Residu $n$-heksana dikeringkan dan dimaserasi dengan pelarut aseton. Filtrat hasil maserasi diuapkan dengan rotary evaporator sehingga diperoleh ekstrak aseton yang berwarna hijau pekat. Ekstrak aseton ditambahkan akuades dengan perbandingan 1:1 kemudian didiamkan selama 24 jam. Selanjutnya dilakukan penyaringan untuk memisahkan filtrat dan klorofil. Ekstrak aseton difraksinasi dengan pelarut amil alkohol, selanjutnya amil alkohol difraksinasi dengan pelarut etil asetat kemudian diuapkan sehingga diperoleh fraksi etil asetat. Simpilisa dan ekstrak yang didapatkan dilakukan analisis penapisan fitokimia yang meliputi tanin, alkaloid, flavonoid, kuinon, saponin, dan steroid/ triterpenoid. Fraksi etil asetat dilakukan pemisahan menggunakan KLT sebagai fase diam berupa silika gel $\mathrm{GF}_{254}$ dan fase gerak berupa $n$-heksana:kloroform:etil asetat (2:5:5). Selanjutnya diuji antioksidan secara kualitatif dan kuantitatif dengan metode DPPH. Noda yang terbentuk dilakukan uji flavonoid dengan reagen penampak bercak uap amonia. Noda positif flavonoid dan positif antioksidan dilakukan pemisahan menggunakan KLT Preparatif.

\section{Analisis}

Isolat yang diperoleh dari hasil isolasi selanjutnya diidentifikasi menggunakan spektrofotometer ultraviolet -cahaya tampak untuk mengetahui panjang gelombang serapan maksimum isolat.

\section{Hasil dan Pembahasan}

Penapisan fitokimia berfungsi untuk mengetahui keberadaan golongan senyawa metabolit sekunder yang terkandung di dalam simplisia serbuk maupun di dalam ekstrak etanol. Penapisan fitokimia yang dilakukan secara kualitatif dengan mengidentifikasi keberadaan suatu senyawa tanpa menentukan kadarnya. Prinsip penapisan fitokimia ialah analisis golongan kimia tumbuhan dengan uji spesifik dengan reagen yang memberikan uji spesifik terhadap golongan kimia tertentu. Golongan yang diidentifikasi pada penelitian ini antara lain alkaloid, flavonoid, saponin, steroid dan triterpenoid. Hasil penapisan fitokimia dapat dilihat pada Tabel 1.

Tabel 1: Hasil uji fitokimia Tempuyung

\begin{tabular}{cccccc}
\hline \multirow{2}{*}{ Sampel } & \multicolumn{5}{c}{ Golongan } \\
\cline { 2 - 6 } & Alkaloid & Flavonoid & Saponin & Steroid & Triterpenoid \\
\hline Serbuk & $(+)$ & $(+)$ & $(+)$ & $(+)$ & $(+)$ \\
E. n-heksana & $(-)$ & $(-)$ & $(-)$ & $(+)$ & $(+)$ \\
E. aseton & $(+)$ & $(+)$ & $(+)$ & $(-)$ & $(-)$ \\
F. etil asetat & $(+)$ & $(+)$ & $(-)$ & $(-)$ & $(-)$ \\
\hline Keterangan: & E $=$ Ekstrak & & & &
\end{tabular}

Hasil uji fitokimia terhadap serbuk daun tempuyung menunjukkan reaksi positif golongan alkaloid, flavonoid, saponin, steroid, dan triterpenoid. Hasil uji fitokimia terhadap ekstrak $n$-heksana hanya menunjukkan reaksi positif golongan steroid dan triterpenoid. Hasil uji fitokimia terhadap ekstrak aseton menunjukkan reaksi positif golongan alkaloid, flavonoid, saponin dan pada fraksi etil asetat menunjukan reaksi positif golongan alkaloid dan flavonoid. Fraksi etil asetat dilakukan identifikasi lebih lanjut menggunakan KLT dengan eluen terbaik nheksana: kloroform:etil asetat (2:5:5) yang menghasilkan 4 noda (Gambar 1).

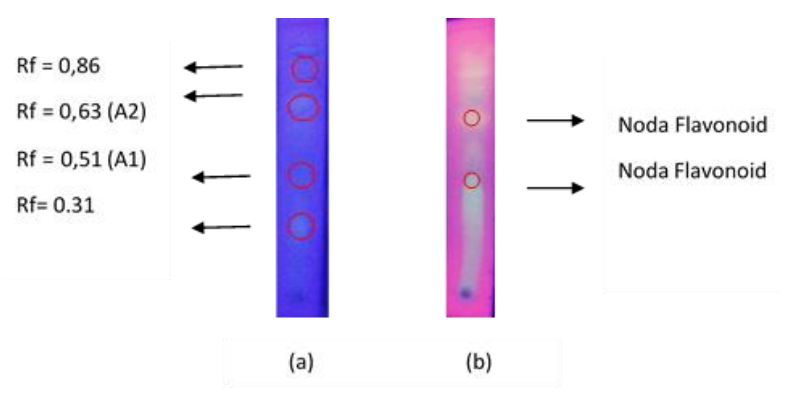

Gambar 1. Harga Rf dan warna noda KLT fraksi etil asetat menggunakan campuran eluen $n$-heksana : kloroform : etil asetat (2:5:5) pada lampu $U V \lambda_{365 \mathrm{~nm}}$ (a) sebelum diuji dengan amonia (b) setelah diuji dengan amonia

Terjadi perubahan warna dari kuning menjadi merah setelah diberi uap amonia. Menurut Markham [9], diduga noda A1 dan A2 merupakan senyawa flavonoid golongan khalkon. Metode yang digunakan untuk mengetahui adanya senyawa antioksidan dalam fraksi etil asetat daun Sonchus arvensis L. adalah metode DPPH. Hasil KLT fraksi etil asetat dengan eluen nheksana: kloroform:etil asetat (2:5:5) disemprot 
menggunakan DPPH yang menghasilkan 2 noda (Gambar 2)

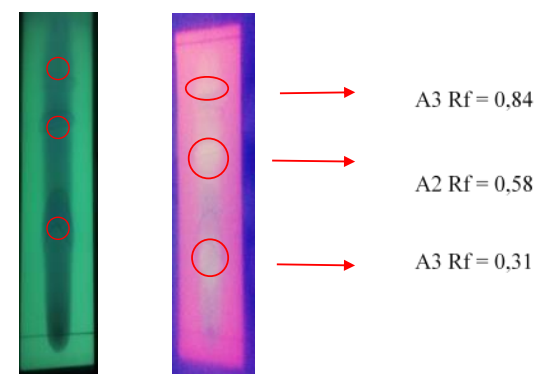

Gambar 2. Hasil KLT fraksi etil asetat setelah disemprot menggunakan eluen campuran $\mathrm{n}$ - heksana : kloroform:etil asetat (2:5:5) pada lampu $U V \lambda_{254 \mathrm{~nm}}$ dan $U V \lambda_{365} \mathrm{~nm}$

(a)

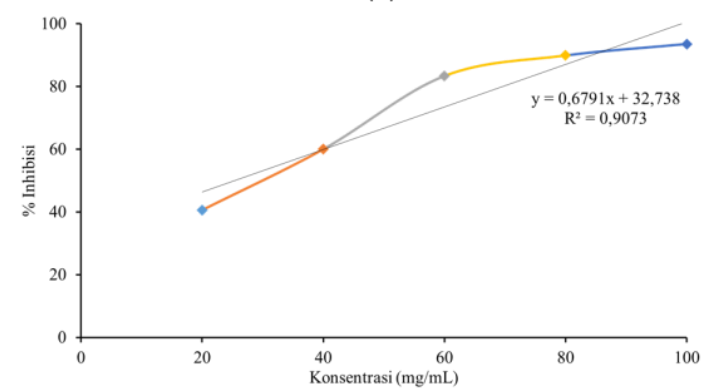

(b)

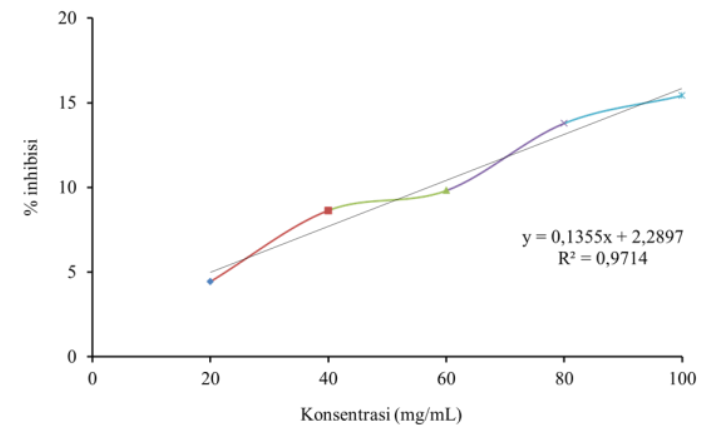

Gambar 3. Grafik hasil pengukuran hubungan antara (a) \% inhibisi dan konsentrasi larutan pembanding kuersetin (b) \% inhibisi dan konsentrasi larutan fraksi etil asetat.

Pada hasil KLT fraksi etil asetat diperoleh 7 noda, tetapi setelah disemprot menggunakan DPPH diperoleh 3 noda yang berwarna kuning yang artinya terdapat 3 komponen yang terpisah yang bersifat antioksidan. Uji kuantitatif aktivitas antioksidan pada sampel (fraksi etil asetat) dilakukan menggunakan metode DPPH (1,1difenil-2-pikrilhidrasil) dengan senyawa kuersetin sebagai pembanding. Uji DPPH dilakukan dengan mengukur absorbansi dan panjang golombang larutan DPPH dalam metanol pada panjang gelombang $515 \mathrm{~nm}$. Uji DPPH digunakan untuk menentukan konsentrasi inhibisi $\left(\mathrm{IC}_{50}\right)$ yang dinyatakan dalam total antioksidan yang digunakan untuk meredam $50 \%$ aktivitas radikal DPPH. Pengukuran dilakukan dengan spektrofotometer UV-Vis, pengukuran berupa absorbansi dari masingmasing konsentrasi sampel $(20 ; 40 ; 60 ; 80 ; 100 \mathrm{mg} / \mathrm{mL})$ sehingga diperoleh grafik \% inhibisi vs konsentrasi.
Dari grafik di atas diperoleh persamaan regresi larutan pembanding kuersetin $\mathrm{y}=0,679 \mathrm{x}+32,73$ dengan nilai $\mathrm{R}=0,907$. Persamaan tersebut menunjukkan hubungan matematis antara konsentrasi dan \% inhibisi, sedangkan nilai r menunjukkan korelasi antara konsentrasi (sumbu $\mathrm{x}$ ) dengan \% inhibisi (sumbu y). Dari data tersebut diperoleh nilai $\mathrm{IC}_{50} 25,43 \mathrm{mg} \mathrm{L}^{-1}$. Fraksi etil asetat menunjukkan persamaan regresi $\mathrm{y}=$ $0,135 \mathrm{x}+2,289$ dengan nilai $\mathrm{R} 0,971$. Dari data di atas dapat diketahui nilai $\mathrm{IC}_{50}$ sebesar $353,41 \mathrm{mg} \mathrm{L}^{-1}$.

Identifikasi isolat A1 dan A2 menggunakan spektrofotometer UV-Vis ditunjukkan pada (Gambar 3).

(a)

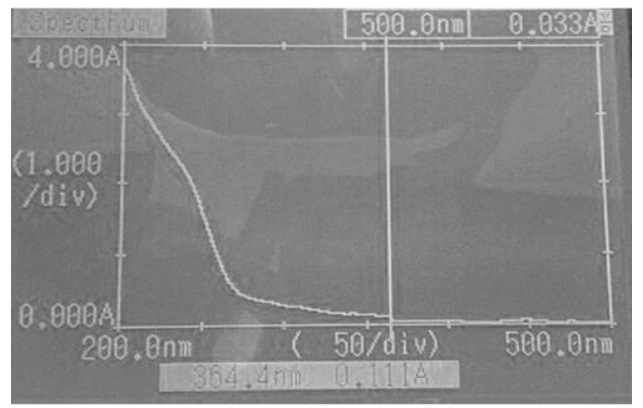

(b)



Gambar 4. Hasil analisis isolat menggunakan spektrofotometer UV-Vis $365,2 \mathrm{~nm}$ (pita I) dan 232,8 $\mathrm{nm}$ (pita II) (isolat A1), 364,4 nm (pita I) dan 245,6 nm (pita II) (isolat A2).

Menurut Markham [9], spektrum khas flavonoid terdiri dari dua pita, pada panjang gelombang $(230 \mathrm{~nm}$ - $270 \mathrm{~nm}$ ) pita I, dan pada (340 nm - $390 \mathrm{~nm}$ ) pita II termasuk dalam senyawa flavonoid golongan khalkon. Isolat A1 dan A2 mempunyai serapan panjang gelombang yang termasuk dalam rentang serapan panjang gelombang senyawa khalkon. Sesuai dengan hasil pada pemisahan senyawa fraksi etil asetat menggunakan KLT yang menunjukan noda A1 dan A2 berfluorosensi kuning dan menunjukan perubahan warna menjadi merah setelah ditambahkan penampak bercak amonia yang menunjukan bahwa isolat A1 dan A2 termasuk dalam senyawa flavonoid golongan khalkon.

\section{Kesimpulan}

Tanaman tempuyung mengandung senyawa alkaloid, flavonoid, saponin, triterpen, dan steroid. Hasil identifikasi menggunakan spektrofotometer UV-Vis menunjukkan bahwa isolat flavonoid yang didapatkan termasuk dalam golongan khalkon. Diperoleh nilai IC $_{50}$ fraksi etil asetat sebesar $353,41 \mathrm{mg} \mathrm{L}^{-1}$, sedangkan 
senyawa antioksidan yang bagus menunjukkan aktivitas antioksidan yang memiliki harga $\mathrm{IC}_{50}$ yang lebih rendah dari 200 ppm (Blois, 1958). Sehingga dapat disimpulkan bahwa fraksi etil asetat tidak berpotensi menjadi antioksidan yang baik.

\section{Daftar Pustaka}

[1] LO Brandsæter, M Goul Thomsen, K Wærnhus, H Fykse, Effects of repeated clover undersowing in spring cereals and stubble treatments in autumn on Elymus repens, Sonchus arvensis and Cirsium arvense, Crop Protection, 32, (2012) 104-110 http://dx.doi.org/10.1016/j.cropro.2011.09.022

[2] Yang-Jun Xu, Shao-Bo Sun, Li-Mei Sun, DongFeng Qiu, Xiu-Jin Liu, Zhi-Bo Jiang, Cheng-Shan Yuan, Quinic acid esters and sesquiterpenes from Sonchus arvensis, Food chemistry, 111, 1, (2008) 9297

http://dx.doi.org/10.1016/j.foodchem.2008.03.028

[3] Zhengxiang Xia, Wei Qu, Haiying Lu, Juqin Fu, Yanli Ren, Jingyu Liang, Sesquiterpene lactones from Sonchus arvensis L. and their antibacterial activity against Streptococcus mutans ATCC 25175, $\begin{array}{llll}\text { Fitoterapia, } & 81, \quad 5, \quad(2010) & 424-428\end{array}$ http://dx.doi.org/10.1016/j.fitote.2009.12.001

[4] J Wadekar, R Sawant, R Naik, B Amruta, Anthelmintic and Antibacterial Potential of Sonchus arvensis Leaves, International Journal of Pharmaceutical Frontier Research, IJPFR, April-June, 2, 2, (2012) 50-55

[5] N Radulović, P Blagojević, R Palić, Fatty acid derived compounds--the dominant volatile class of the essential oil poor Sonchus arvensis subsp. uliginosus (Bieb.) Nyman, Natural product communications, 4, 3, (2009) 405-410

[6] Yazid Murtadlo, Isolasi, identifikasi senyawa alkaloid total daun tempuyung (Sonchus arvensis linn) dan uji sitotoksik dengan metode BSLT (Brine Shrimp Lethality Test), Chem Info Journal, 1, 1, (2013) 379-385

[7] Meutia Rumondang, Isolasi, Identifikasi Dan Uji Antibakteri Senyawa Triterpenoid Dari Ekstrak nHeksana Daun Tempuyung (Sonchus arvensis L.), Chem Info Journal, 1, 1, (2012) 156-164

[8] Wulan Yuliarti, Isolasi, Identifikasi dan Uji Antioksidan Asam Fenolat dalam Daun Tempuyung (Sonchus Arvensis L.) dengan Metode 1, 1-Difenil2-Pikrilhidrasil (DPPH), Chem Info Journal, 1, 1, (2012) 294-304

[9] KR Markham, Cara Mengidentifikasi Flavonoid, ITB, Bandung, 1988. 